\title{
The nutritional cost of measles in Africa
}

\author{
M B DUGGAN, J ALWAR, AND R D G MILNER \\ Department of Paediatrics, Sheffield University, Sheffield Children's Hospital, and Kenyatta National \\ Hospital, Nairobi
}

SUMMARY A 24 hour energy balance study was carried out on 20 black Kenyan children with acute measles and repeated after recovery. The energy content of a weighed 24 hour food intake and of a simultaneous collection of faeces and urine was determined by bomb calorimetry. Energy expenditure was measured by indirect calorimetry using a purpose built flow over calorimeter. The nutritional state of the children was assessed by anthropometry at the time of each study and during convalescence. The results showed a fall of roughly $75 \%$ in the intake of gross and metabolisable energy during measles, while the resting energy expenditure was little affected. Thus the severe degree of negative apparent energy balance observed during measles is the combined effect of underfeeding in ill children, and failure, during starvation related to infection, of the early fall in metabolic rate that characterises simple underfeeding.

Infection is commonly accompanied by a period of negative energy and nitrogen balance. This results from a reduction in dietary energy intake, ${ }^{12}$ a sustained or increased level of energy expenditure, ${ }^{3}$ and an enhanced rate of endogenous protein catabolism. ${ }^{4}$ The development of syndromes of malnutrition after underfeeding in adults with postoperative infection has also been documented. ${ }^{5}$ Despite circumstantial evidence of a causative link with malnutrition, ${ }^{6}$ infection is often stated to be of secondary importance in the genesis of Third World malnutrition. ${ }^{7}$ It was, therefore, of interest to determine experimentally the nutritional cost of a common childhood infection.

Measles was a suitable model for study; the severe illness in Africa is associated with anorexia, stomatitis, ${ }^{8}$ and diarrhoea with loss of protein into the gut. ${ }^{9}$ It is also followed by a period of depressed cell mediated immunity, favouring the development of opportunistic infection, including protracted diarrhoea. ${ }^{10}$ Measles has also been implicated as a cause of malnutrition. ${ }^{11} 12$

The contribution to the nutritional cost of measles of changes in energy intake or expenditure may be compared by detailed study of energy balance during the acute infection. It is also possible by appropriate selection of subjects to investigate the relation between initial nutritional state and the nutritional cost of measles infection. A 24 hour energy balance study was carried out on 20 black Kenyan children during their admission with measles to the Infectious Diseases Hospital, Nairobi. The children were readmitted for the control study after convalescence, the course of which was monitored during regular home visits.

\section{Subjects and clinical management}

Table 1 summarises the clinical features of measles in the 20 children studied. Diagnosis was based in

Table 1 Prevalence and duration of the major clinical features of measles in the 20 children studied

\begin{tabular}{lllll}
\hline $\begin{array}{l}\text { Stage of the } \\
\text { infection }\end{array}$ & Clinical feature & $\begin{array}{l}\text { Prevalence } \\
(\%)\end{array}$ & \multicolumn{2}{l}{ Duration in days } \\
\cline { 3 - 5 } & & & Average & Range \\
\hline Prodromal & Fever & 100 & 6 & $3-14$ \\
period & Anorexia & 100 & 6 & $3-30$ \\
& Diarrhoea & 70 & 5 & $1-7$ \\
& Cough & 20 & 6 & $3-10$ \\
Exanthem & Rash & 100 & 4 & $3-5$ \\
(hospital & Conjunctivitis & 80 & $*$ & $*$ \\
admission) & Stomatitis & 95 & $*$ & $*$ \\
& (palatal involvement) & 30 & $*$ & $*$ \\
& Otitis media & 35 & $*$ & $*$ \\
& Laryngitis & 40 & $*$ & $*$ \\
& Bronchopneumonia & 30 & $*$ & $*$ \\
& Anorexia & 65 & & 10 \\
Convalescence & Loss' of walking & 60 & 19 & $10-40$ \\
& Otitis media & 20 & $*$ & $*$ \\
& Diarrhoea & 45 & $*$ & $*$ \\
& Bronchopneumonia & 10 & 5 & $4-7$ \\
\hline
\end{tabular}

*Not quantified. 
Table 2 Nutritional state of the 20 children at time of admission with acute measles and net changes in several nutritional variables during convalescence

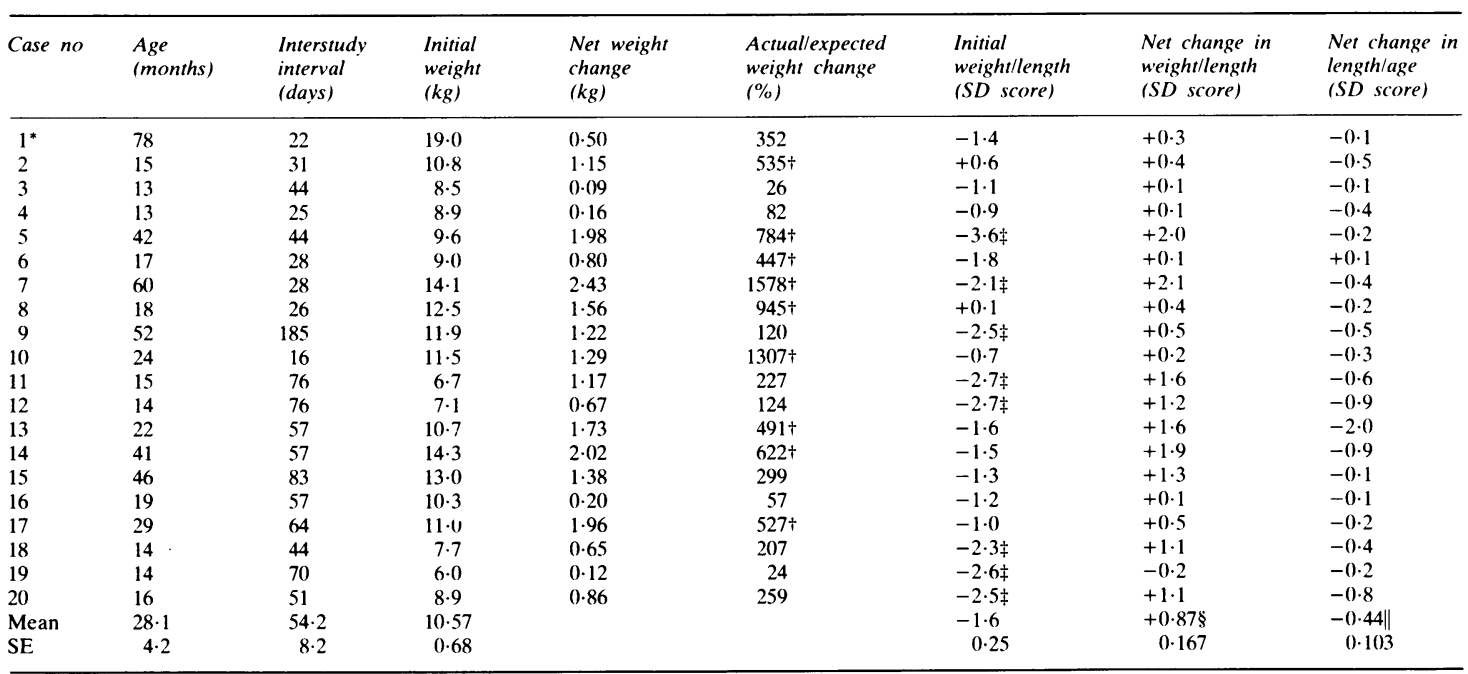

*Only female subject.

†'Rapid' weight gain; rate in excess of $400 \%$ of reference weight gain.

$\ddagger$ Malnutrition indicated by deficit $>2.0 \mathrm{SD}$ from weight/length reference median.

§Significant $p<0.01$ improvement in mean SD score for weight/length.

$\|$ Significant $\mathrm{p}<0.01$ deterioration in mean SD score for length/age.

each case on the presence of an unequivocal rash, which was maculopapular in 13 children and black and haemorrhagic in seven. Ten children entered the study within 24 hours of the occurrence of the measles rash, and all were studied within five days of its eruption. Routine medical care was maintained during the 24 hour observation period, including administration of standard antibiotic prophylaxis. The standard hospital 'toddler diet', which is based on traditional Kenyan foods, was supplied during both clinical studies. Interference with the customary parental supervision of the children's food intake was limited to the essential cooperation involved in collecting the duplicate diet.

Table 2 illustrates the nutritional state of the children at entry to the study. Eight children were identified as malnourished on the basis of a deficit of more than $2 \mathrm{SD}$ from the weight/length reference median. ${ }^{13} 1415$

\section{Experimental methods}

Energy expenditure was measured by indirect calorimetry, using a purpose built system (Figure) capable of measuring both the oxygen and carbon dioxide components of the respiratory gaseous exchange. The accuracy of the assembled calorimetry, whose calibration is described elsewhere, ${ }^{15}$ was shown in oxygen recovery tests to be mean (SD) $103(3 \cdot 5 \%)$. The metabolic rate was calculated from the respiratory gaseous exchange and the urinary nitrogen excretion. ${ }^{16}$

Between one and five measurements of metabolic rates were made during sleep or quiet rest, each of at least 20 minutes' duration, during the 24 hour observation period. Measurements made up to and including four hours after a meal of at least $25 \mathrm{~kJ}$ were arbitrarily defined as 'post prandial', while those made after a longer period were defined as measurements of 'resting metabolism'. The number of measurements made on each subject was dependent both on the child's compliance and on mains electricity. Bias due to unequal numbers of observations was eliminated by calculating a mean value for each subject of all measurements of metabolic rate and for respiratory quotient made during either resting or post prandial metabolism (Table 3).

The dietary intake of gross energy was measured by collecting a 24 hour duplicate diet, homogenising it, drying an aliquot and determining its heat of combustion by bomb calorimetry. Faeces and urine were collected over the same period using urine collecting bags and lined disposable napkins as indicated. Faecal material was extracted from the napkins,${ }^{17}$ dried, and then analysed by bomb calor- 


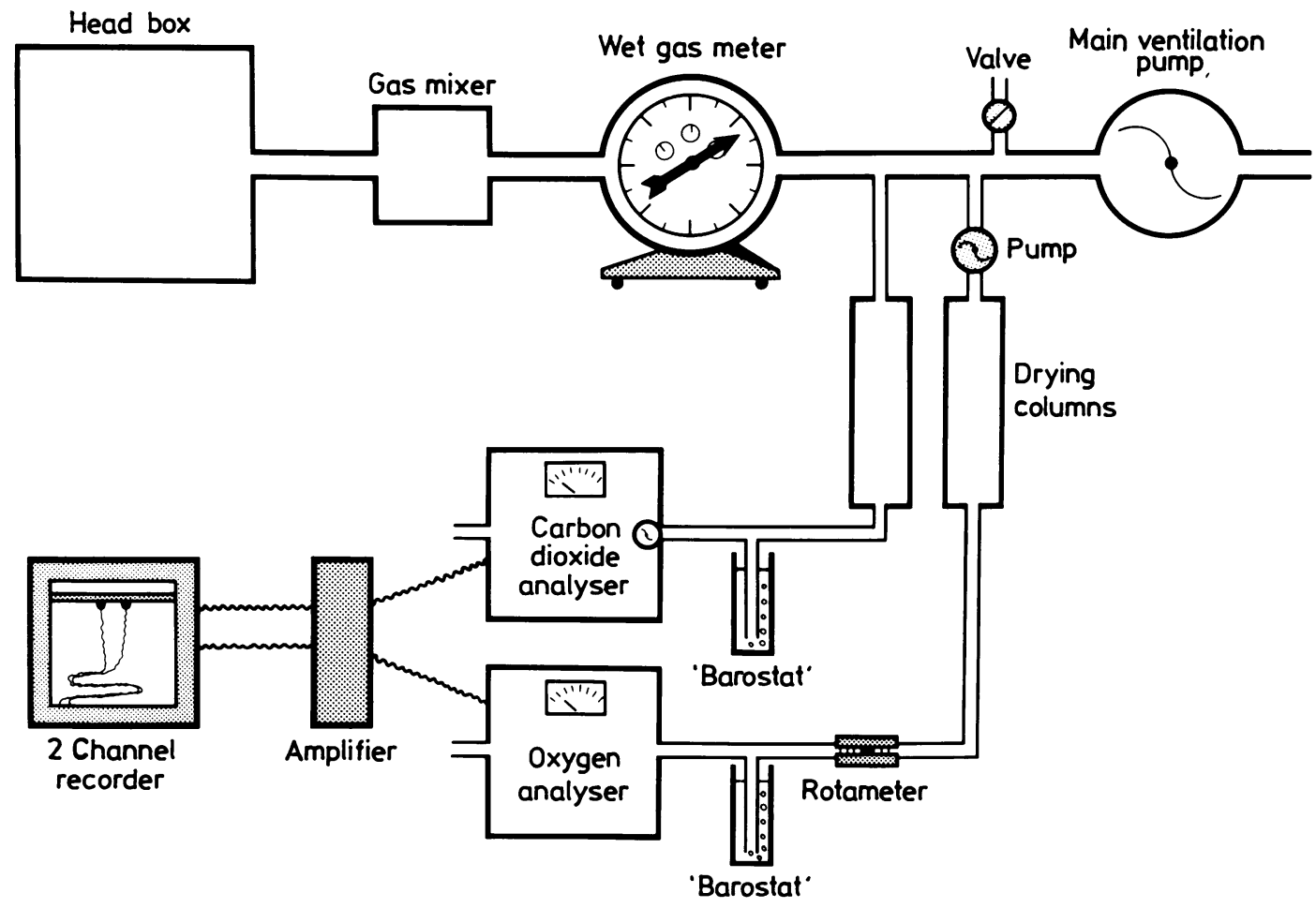

Figure The flow over calorimeter: circuit diagram.

Table 3 Energy expenditure (metabolic rate) in 20 children studied during and after acute measles and in relation to food intake. Values are mean (SE)

\begin{tabular}{|c|c|c|c|c|}
\hline \multirow[t]{2}{*}{ Variable measured } & \multicolumn{2}{|c|}{ Infection (children studied during measles) } & \multicolumn{2}{|c|}{ Control (children studied after measles) } \\
\hline & Resting & Post prandial & Resting & Post prandial \\
\hline Oxygen consumption $(\mathrm{ml} / \mathrm{kg} / \mathrm{min})$ & $8 \cdot 8(0 \cdot 34)$ & $8 \cdot 2(0 \cdot 67)$ & $9 \cdot 3(0 \cdot 32)$ & $10 \cdot 3(0.46)$ \\
\hline Metabolic rate $(\mathrm{kJ} / \mathrm{kg})$ & $10.7(0.39)$ & $9.7(0.61)$ & $11 \cdot 3(0 \cdot 36)$ & $12.8(0.58)$ \\
\hline Respiratory quotient & $0.83(0 \cdot 02)$ & $0.80(0 \cdot 03)$ & $0.98(0.03)$ & $0.93(0.02)$ \\
\hline No of subjects* & 18 & 8 & 18 & 16 \\
\hline Total no of observations & 30 & 19 & 31 & 28 \\
\hline
\end{tabular}

*No of subjects (mean values of all observations) studied at the stated period. Statistical analysis by Student's $t$ test. Mean level of resting metabolic rate and resting oxygen consumption similar in both studies. $\mathrm{p}<0.05$ (Paired data) for post prandial $v$ resting metabolic rates in control; $\mathrm{p}<0 .(05$ (paired data) for post prandial metabolic rate in control $v$ post prandial metabolic rate in infection; $p<0$ ).(05 (unpaired data) for post prandial $v$ resting oxygen consumptions in control; $p<0.01$ (unpaired data) for post prandial oxygen consumption in control $v$ post prandial oxygen consumption in infection. Mean level of resting respiratory quotient significantly higher in control than infection, $\mathrm{p}<0.01$ (paired data).

imetry. Food and faeces were analysed in duplicate with a third analysis when results failed to agree within $3 \%$. The energy content of urine was calculated from its urinary nitrogen content, which was determined by a modified Kjeldahl method. Bomb calorimetry was carried out in the Wellcome Trust Research Laboratories, Nairobi, and urinary nitrogen analyses in the Department of Surgery Laboratories, Northern General Hospital Sheffield, by $\mathrm{Mr}$ A Prescott. Urine was stored at $-20^{\circ} \mathrm{C}$ and transported frozen for analysis. Results of these analyses were then used to calculate the 24 hour intake of gross, digestible, and metabolisable energy.

Full auxological measurements were made at the beginning of each 24 hour clinical study, and children were weighed at each home visit. Weight and length measurements using a basket type beam 
balance (CMS, London) accurate to $10 \mathrm{~g}$ and an infant measuring table (Holtain) accurate to $0.1 \mathrm{~cm}$ were used to calculate the weight:length ratio. This was referred to the reference standard recommended by the World Health Organisation ${ }^{14}$ using the standard deviation score method of presenting data to facilitate parametric statistical analysis. ${ }^{18}$ The weight measurements were also used to calculate the net rate of weight gain during convalescence, which was expressed as a percentage of the reference rate adjusted for age. Informed verbal consent was obtained from all parents, and the study was considered acceptable by the Medical Research Ethical Committee of Kenyatta National Hospital.

\section{Results}

The magnitude and pattern of energy expenditure. In children studied with acute measles the mean level of the metabolic rate was similar during both post prandial and resting metabolism, with no evidence of the significant $(\mathrm{p}<0.05)$ post prandial enhancement of metabolic rate that was observed in the control study (Table 3 ). Thus the level of the resting metabolic rate was similar in both studies, while the mean post prandial metabolic rate was significantly higher in the control study $(\mathrm{p}<0.05)$, the difference representing $24 \%$ of the mean value of the post prandial metabolic rate in control patients. Paucity of data on the post prandial metabolic rate during infection precluded analysis of the relation between the magnitude of this rate and initial nutritional state.

The mean level of the respiratory quotient during both resting and post prandial metabolism was significantly different in infection and control studies $(p<0.001)$. The significant increase in the mean respiratory quotient of recovered children was true both for well nourished and previously mal nourished children $(\mathrm{p}<0.01$ in each case $)$. The mean level of the respiratory quotient in the control study was, however, higher in those children who had initially been malnourished $(p<0 \cdot 05)$, although this was not attributable to rapid rates of weight gain during convalescence.

The intake of gross, digestible, and metabolic energy. The mean level of intake of gross energy was significantly reduced during measles $(\mathrm{p}<0 \cdot 001)$, this reduction, when expressed in $\mathrm{kJ} / \mathrm{kg} / 24 \mathrm{~h}$, representing a $75 \%$ fall in the energy intake. The mean level of gross energy intake was not significantly influenced in either study by the initial nutritional state. While the faecal energy loss was, in absolute terms, greater in the control study, the digestible energy represented a similar percentage of gross energy in each study (Wilcoxon's rank sum test). Conversely, although the urinary energy loss was of similar magnitude in both studies, the consequent percentage reduction in energy intake was greater during infection $(p<0 \cdot 05$, Wilcoxon's ranked sum test for paired data) (Table 4). Thus the percentage of gross energy intake that was metabolisable was significantly smaller during acute measles than after recovery $(p<0 \cdot 05$, Wilcoxon's ranked sum test).

Apparent energy balance. As a result of the fall in metabolisable energy intake and a sustained level of energy expenditure during measles, 17 of the 18 children on whom data were complete were in negative apparent energy balance at the end of the 24 hour study. Conversely, 12 of 18 children were in positive apparent energy balance during the control study. The magnitude of the mean negative energy balance during measles is given by $-169(21 \cdot 7)$ $\mathrm{kJ} / \mathrm{kg} / 24 \mathrm{~h}$ and of positive balance after recovery by $67(30 \cdot 0) \mathrm{kJ} / \mathrm{kg} / 24 \mathrm{~h}$.

Convalescence. As illustrated in Table 2 the mean level of nutrition as estimated by the weight/length SD score had significantly improved by the time of the control study $(p<0 \cdot 01)$. Nevertheless, this was

Table 4 Energy intake and resting energy expenditure by 20 children during and after measles; illustrating proportions of gross energy digestible and metabolisable after energy loss in faeces and urine, respectively. Values are mean (SE)

\begin{tabular}{|c|c|c|c|c|c|c|}
\hline & \multicolumn{3}{|l|}{ Infection } & \multicolumn{3}{|l|}{ Control } \\
\hline & $k J / 24 h$ & $\%$ & $k J / k g / 24 h$ & $k J / 24 h$ & $\%$ & $\mathrm{~kJ} / \mathrm{kg} / 24 \mathrm{~h}$ \\
\hline Gross energy intake & $897(126 \cdot 0)$ & 100 & $94.1(18.5)^{*}$ & $4288(4.57 \cdot 2)$ & 100 & $374 \cdot 2(29 \cdot 6)$ \\
\hline Faecal energy loss & $95(28 \cdot 8)$ & & $6.5(1.5)$ & $4.37(75.4)$ & & $36.7(7.2)$ \\
\hline Digestible energy intake & $825(121 \cdot 2)$ & $92 \div$ & 9()$\cdot 3(17 \cdot 6)$ & $3895(416.6)$ & 87 & $322 \cdot 1(33 \cdot 3)$ \\
\hline Urinary energy loss & $104(12.9)$ & & $10 \cdot 9(1 \cdot 3)$ & $175(32 \cdot 4)$ & & $12 \cdot 8(1.9)$ \\
\hline Metabolisable energy intake & $742(123 \cdot 6)$ & $72 \div$ & $81 \cdot 5(17 \cdot 5)$ & $3731(489 \cdot 4)$ & 83 & $309 \cdot 4(32 \cdot 8)$ \\
\hline Resting energy expenditure & $2574(18.3 \cdot 2)$ & & $256.6(9 \cdot 34)$ & $3180(226 \cdot 2)$ & $272 \cdot 2(8 \cdot 66)$ & \\
\hline
\end{tabular}

${ }^{*}$ Gross energy intake significantly reduced during measles, $\left.\mathrm{p}<0\right) \cdot(0) 1$ (Student's $t$ test for paired data).

$\div$ Digestible energy equivalent to similar percentage of gross energy intake in both studies (Wilcoxon's paired rank sum test).

$\$$ Metabolisable energy intake equivalent to significantly lower percentage of gross energy intake during measles, $p<0 \cdot(05$ (Wilcoxon’s paired rank sum test). 
accompanied by a significant deterioration in the mean length/age SD score $(p<0 \cdot 01)$. Neither initial nutritional state nor the presence of complicating pneumonia was associated with a lower rate of weight gain. Children with rapid rates of weight gain, however, had a significantly lower prevalence of diarrhoea during convalescence $\left(p<0 \cdot 01, \quad \chi^{2}\right.$ analysis). In summary, measles infection was characterised by a $75 \%$ fall in gross and metabolisable energy intake. Energy expenditure remained at control levels, although the post prandial enhancement of the metabolic rate was absent during infection. The satisfactory mean rate of weight gain during convalescence did not seem to be influenced by the initial nutritional state nor the severity of the clinical infection, although it was significantly inhibited by late onset diarrhoea.

\section{Discussion}

These data show that the normal pattern of positive energy balance in childhood may be reversed by measles infection. The major factor responsible was the grave reduction in the intake of gross dietary energy. Although this has been quantified only for a 24 hour period, the universal parental reporting of previous anorexia (Table 1) suggests that negative energy balance was of a longer duration.

The development of overt malnutrition after infections complicated by anorexia and often by starvation treatment is not merely an effect of underfeeding. ${ }^{2}{ }^{19}$ Starvation associated with infection results in a more rapid and severe weight loss than does starvation alone. ${ }^{20}$ This seems to be due to an increase in resting metabolic expenditure during infection stress ${ }^{51}$ rather than the early fall in metabolic rate that characterises starvation or underfeeding. $^{22}{ }^{2.3}$ The present data, while not immediately showing an increase in resting metabolic rate during measles, afford no evidence of any metabolic adaptation to starvation. However, review of the respiratory quotient data on the control group, $67 \%$ of whom were in positive apparent energy balance, eating a high carbohydrate diet, suggests a further interpretation. The high mean value of the resting respiratory quotient, and the fact that the value for respiratory quotient exceeded 1.0 in 20 out of 31 -that is, in $65 \%$ of all observations of resting respiratory quotient-was strongly indicative of net lipogenesis from carbohydrate. The persistence of lipogenesis-that is, biosynthesis-long after the post prandial period suggested that the resting metabolic rate included the energy cost of this biosynthesis. As net biosynthesis was manifestly absent in the infection study, the sustained level of the resting metabolic rate at this time was probably indicative of an increased basal metabolic rate. Thus the basal metabolic rate seems to be increased in children with measles as it is with other viral infections. ${ }^{24}$

No attempt was made to interpret weight changes during the acute febrile illness, as they were probably influenced by alteration in fluid as well as energy balance at this time.

Although there was a high prevalence of secondary infection during convalescence (Table 1), only in the case of diarrhoea was a significant effect observed. An even higher prevalence of diarrhoea after measles with graver nutritional sequelae has been reported in a rural population with less easy access to mains water. ${ }^{9}$ The overall improvement in nutritional state, estimated by the mean weight/ length SD score, seemed to be the combined effect of an increase in weight and sluggish or absent linear growth. A link between measles and nutritional stunting has also been reported in Nigerian children. ${ }^{25}$

Malnutrition did not seem to influence the magnitude of negative energy balance observed in the present study. However, catabolic weight loss to meet a given energy shortfall would probably be greater in an already lean child because of quantitative differences in the energy stored in lean and fatty tissue. This supposition accords with the observation of a more severe weight loss in postsurgical sepsis in lean adults. ${ }^{21}$

The return of all 20 children for control study was the result of regular surveillance, accompanied by medical intervention, during the period of convalescence. Nevertheless, four children failed to achieve reference rates of weight gain, and one child, whose recovery was interrupted by malaria and pneumonia, had become severely wasted by the time of the second study.

The nutritional cost of measles has been quantified by means of a 24 hour energy balance study. The resultant negative apparent energy balance is the combined effect of a grave reduction in the intake of gross and metabolisable energy and a sustained level of resting metabolic expenditure. Stopping of growth during infection is shown by absence of the usual post prandial increase in metabolic rate and suggested by the pronounced fall in the level of respiratory quotient during acute measles. Despite a period of negative energy balance most children gained weight satisfactorily during convalescence, although linear growth had slowed. Four children, only one of whom was previously malnourished, failed to thrive throughout follow up. The experimental results of this study support previous circumstantial evidence that measles, and, by inference, other infections associ- 
ated with negative energy balance, are probably implicated in the genesis of childhood malnutrition.

M B Duggan was supported during this study by a Wellcome Trust Research Fellowship. The authors acknowledge the cooperation of Dr A Jan Mohammed, medical superintendent, Infectious Diseases Hospital, and Mrs $\mathrm{H}$ Watkins, laboratory superintendent, Wellcome Trust Research Laboratories, Nairobi, and of Dr G Tobin, Department of Physiology of the University of Leeds, for advice on the design and construction of the calorimeter.

\section{References}

' Beisel WR. Magnitude of the host nutritional response to infection. Am J Clin Nutr 1977;30:1236-47.

${ }^{2}$ Rutishauser IHE. Factors affecting the intake of energy and protein by Ugandan preschool children. Ecology, Food and Nutrition 1974;3:213-22.

${ }^{3}$ Halmagyi DF, Kinney JM. Metabolic rate in acute respiratory failure complicating sepsis. Surgery 1975;77:492-7.

${ }^{4}$ Clowes GHA, George BC, Villee CA, Sarazis CA. Muscle proteolysis induced by a circulating peptide in patients with sepsis or trauma. $N$ Engl J Med 1983;308:545-52.

5 Bistrian BR. Interaction of nutrition and infection in the hospital setting. Am J Clin Nutr 1977;30:1228-32.

6 Rowland MGM, Cole TJ, Whitehead RD. A quantitative study into the role of infection in determining nutritional status in Gambian village children. Br J Nutr 1977;37:411-50.

7 Waterlow JC. Nutrition for the world's children: what do we need to know? In: Wharton BA, ed. Topics in paediatrics 2 . Nutrition in childhood. Tunbridge Wells: Pitman Medical, 1980.

${ }^{8}$ Whittle HC, Sandford Smith J, Kogbe OI, Dosseter J, Duggan MB. Severe ulcerative herpes of mouth and eye following measles. Trans $R$ Soc Trop Med Hyg 1979;73:66-9.

9 Dosseter JFB, Whittle HC. Protein losing enteropathy and malabsorption in acute measles. Br Med J 1975;ii:592-3.

${ }^{10}$ Koster FT, Curlin GC, Aziz KMA, Hague A. Synergistic effect of measles and diarrhoea on nutrition and mortality in Bangladesh. Bull WHO 1981;59:901-8.

11 Morley D. The severe measles of West Africa. Proceedings of the Royal Society of Medicine 1964;57:846-9.

12 Cherian A, Duggan MB, Sterken E. The epidemiology of malnutrition in young children in Zaria, Nigeria. Ecology, Food and Nutrition 1985;16:1-13.
13 United States Department of Health Education and Welfare. Comparison of body weight and height of groups of children. Atlanta, Georgia: US Department of Health Education and Welfare, 1974

14 Waterlow JC, Buzina R, Keller M, Lane JM, Nichaman MZ, Tanner JM. Presentation and use of height and weight data for the comparison of the nutritional status of groups of children under the age of 10 years. Bull WHO 1977;55:489-98.

15 Duggan MB, Tobin G, Milner RDG. Proceedings of the European nutrition workshop on energy metabolism. Netherlands: University of Wageningen 1984. 1985:113-8.

${ }^{16}$ Lusk G. Elements of the science of nutrition. 4th ed, 1928. New York: Academic Press. Reprinted 1978.

${ }^{17}$ Brooke OG, Alvear J, Arnold M. Energy retention, energy expenditure and growth in healthy immature infants. Pediatr Res 1979;13:215-20.

${ }^{18}$ Karlberg P, Taranger J, Engstrom I, Lichtentein H, Svennberg Redogren I. The somatic development of children in a Swedish urban community. Acta Paediatr Scand 1976;258:1-31.

19 Mata LJ, Kromal RA, Urrutia JJ, Garcia B. Effect of infection on food intake and the nutritional state; perspective as viewed from the village. Am J Clin Nutr 1977;30:1215-27.

${ }^{20}$ Long CL. Energy balance and carbohydrate metabolism in infection and sepsis. Am J Clin Nutr 1977;30:1301-10.

${ }^{21}$ Halmagyi DFJ, Broell J, Gump FE, Kinney JM. Hypermetabolism in sepsis; correlation with fever and tachycardia. Surgery 1974;75:673-70.

22 Benedict FG. A study of prolonged fasting. Washington: Carnegie Institute of Washington, 1915. Publication no 203.

${ }^{23}$ Keys A, Brozek J, Henschel A, Mickersen O, Taylor HL. Basal metabolism. In: Keys A, Brozek J, Henschel A, Mickersen O, Taylor HL. The biology of human starvation. Minneapolis: The University of Minnesota, 1950.

24 Wannemacher RW, Jr, Dintermen RE, Pekarer RS, et al. Urinary amino acid excretion during experimentally induced sandfly fever in man. Am J Clin Nutr 1975;28:110-18.

${ }^{25}$ Cherian A, Duggan MB, Sterken E. Anthropometric measurement of malnutrition in Zaria, Nigeria. Ann Trop Paediatr $1983 ; 3: 143-52$.

Correspondence to Dr M B Duggan, Department of Paediatrics, The Children's Hospital, Sheffield S10 2TH.

Received 13 August 1985 